\title{
Angiographic Predictors of Spontaneous Obliteration of Transarterial Partially Embolized Brain Arteriovenous Malformations.
}

\section{Ahmed Elsayed Sultan ( $\sim$ ahmedsultan173@yahoo.com )}

Alexandria Medical School: Alexandria University Faculty of Medicine https://orcid.org/0000-0002-

8733-9634

\section{Tamer Hassan}

Somoha University Hospital, Alexandria

Tamer Ibrahim Metwaly

Somoha University Hospital, Alexandria

\section{Research Article}

Keywords: arteriovenous malformations, angiographic cure, partial embolization, complete obliteration, venous drainage, flow stasis.

Posted Date: July 20th, 2021

DOl: https://doi.org/10.21203/rs.3.rs-647862/v1

License: (c) (i) This work is licensed under a Creative Commons Attribution 4.0 International License. Read Full License

Version of Record: A version of this preprint was published at Interventional Neuroradiology on March 31 st, 2022. See the published version at https://doi.org/10.1177/15910199221092579. 


\section{Abstract}

Background: spontaneous obliteration of cerebral arteriovenous malformations is uncommon but could occur after partial embolization.

\section{Materials and methods:}

A retrospective study of 140 patients that underwent embolization for cerebral AVMs from 2005 to August 2019 using liquid embolic agents. The angiographic outcome of patients was classified as regard complete embolization, partial embolization, and complete obliteration after partial embolization. The parameters studied included size, location, number of arterial feeders, number of draining veins, rupture status, embolic agent, and patient factors as well.

Results: The study patients included 74 (53\%) females and 66 (47\%) males. Their age ranged from 7 to 43 years old. One hundred and eight patients (77\%) presented with hemorrhage. The AVM grades were grade II in $57(40.7 \%)$ patients and grade III in $56(39.3 \%)$ patients. Sixty-one (43.57\%) patients were treated by n-Butyl Cyanoacrylate and 71(50.71\%) patients were treated with Onyx, and both materials were used together in 8 cases. Follow-up angiography was done from 6 to 36 months after embolization. The rate of complete occlusion in all patients was $61.43 \%$ (86 patients). There were three groups of patients, the first group had complete occlusion of the nidus at the time of embolization and included 68 (48.57\%) patients. The second group had partial embolization with partial occlusion of the nidus 54 patients (38.57\%). The 3rd group included 18 patients (12.85\%) with complete nidal occlusion on follow up after partial embolization.

The delay in the venous drainage of the AVM to the late arterial phase or early venous phase with flow stasis was a significant predictor of future obliteration on follow up after partial embolization. Other significant parameters that were associated with the progressive disappearance of the AVM nidus on follow up after partial embolization are presentation with hemorrhage, AVMs size less than $3 \mathrm{~cm}$, the presence of single draining or double draining veins, superficial venous drainage, and one or 2 arterial feeders.

Conclusion: spontaneous closure of intracranial arteriovenous malformations after partial embolization may be encountered in cases of stasis of flow during embolization procedure with a delay of the venous drainage. A long-term follow-up of more cases over many years is required to confirm the validity of this conclusion.

\section{Declarations}

Funding: This research did not receive any funding from any source.

Conflict of interest: there is no conflict of interest for all authors. 
Ethical approval: All procedures performed in studies involving human participants were in accordance with the ethical standards of the institutional and/or national research committee and with the 1964 Helsinki declaration and its later amendments or comparable ethical standards. The research was accepted by the ethics committee of Faculty of Medicine Alexandria University Serial no. 03034516

Informed consent: Informed consent was obtained from all individual participants included in the study.

Authors' contributions: Conception and design: Ahmed Sultan. Acquisition of data: Ahmed Sultan, Tamer Hassan, and Tamer Metwaly. Analysis and interpretation of data: Ahmed Sultan, Tamer Hassan, and Tamer Metwaly. Manuscript submission: Ahmed Sultan. Statistical analysis: Ahmed Sultan.

Availability of data and material (data transparency): not applicable

Code availability (software application or custom code): not applicable

\section{Introduction}

Pial arteriovenous malformations although rare, are a common cause of stroke in the young population. Their management carries great controversy worldwide. Microsurgery plays a major role in the immediate eradication with a good result in low-grade lesions, but it carries a high rate of morbidity in the high-grade ones[23,26]. Radiosurgery can be used in deep lesions less than $3 \mathrm{~cm}$ with a success rate of $80 \%$ after $2-3$ years[7]. The role of endovascular embolization is now increasing with a comparable obliteration rate, low morbidity, and mortality $[4,5,8,15,23,25,27]$. It can be done alone or in combination with other modalities[4,5,7,19]. Partial embolization is used frequently in the literature to occlude an aneurysm or high flow fistula or part of the multisession treatment of the nidus. some studies indicated that partial embolization may carry the risk of increased hemorrhage $[6,10,16,23,26]$. Many previous studies reported the disappearance of AVM nidus after partial embolization or even after surgery[1-3,9,11,16,20,23,24,28]. We experienced obliteration of the nidus after unintended partial or subtotal embolization in some of our cases of embolization. Those cases were fortunately discovered on follow up. The study is discussing the possible underlying factors standing behind this phenomenon.

\section{Materials And Methods}

A retrospective study in a consecutive series of 140 patients underwent embolization for an AVM from 2005 to August 2019 using liquid embolic agents. The occlusion of AVM after embolization was studied. Patients were categorized into 3 groups. The first group included patients with complete obliteration at the time of embolization, the second one included cases with partial obliteration after partial embolization, and the 3rd included patients with complete obliteration after partial embolization. The parameters of the studied groups included the demographic and clinical data: (1) age, sex; (2) clinical presentation; (3) history of prior hemorrhage; and (4) Spetzler-Martin (SM) grading scale and other angioarchitecture characteristics (table 1,2). MRI and CT scans were done in all cases. CTA was done in some cases. a full assessment of the whole cerebral circulation by digital subtraction angiography was 
done in all cases in a separate procedure. All patients presented with hemorrhage were embolized after the resolution of the hematoma or after evacuation.

The Femoral artery approach was used in all cases. general anesthesia with endotracheal intubation was used in all cases. A 6-F guiding catheter (Envoy; Codman, USA) or (Chapron, Microvention), to guard against blood clotting inside the guiding catheter Continuous flushing of normal saline $(0.9 \mathrm{NaCl})$ containing heparin ( $5000 \mathrm{U} / 500 \mathrm{~mL}$ saline) and $5 \mathrm{mg}$ nimodipine/ $500 \mathrm{~mL}$ saline to prevent vasospasm. Heparin was reversed using protamine before microcatheter removal. Superselective navigation of the AVM feeders was done using flow directed microcatheters after complete cerebral angiography. careful analysis of the super-selective angiogram was done to assess the optimum position of the tip of the microcatheter inside the nidus, on-passage arteries, intranidal aneurysms, high flow fistulas, and vein location. road-mapping was used during material injection in all lesions.

The embolizing agent was chosen according to the angioarchitecture of the nidus. Onyx 18 (Medtronic) was used in lesions with multiple compartments and feeders with enough length for the reflux of embolizing material. Onyx was slowly injected into the nidus under continuous roadmap fluoroscopy using the "push and plug" technique. If any reflux along the microcatheter was observed or the material reached the draining vein, the injection was stopped for 1-2 minutes and then resumed to redirect Onyx to different parts of the lesion. Control angiographies were done regularly during Onyx injection to assess the nidus filling and the venous drainage. A DMSO-compatible delivery microcatheter was used including Marathon (Medtronic), Apollo (Medtronic), or Sonic (Balt, France). Microwires included Mirage (Medtronic) and hybrid (Balt).

N-Butyl Cyanoacrylate (NBCA) (Trufill; Cordis, Miami Lakes, FL) was used in direct high flow fistula and feeders with no safe distance for the reflux of the embolizing agent. The concentration of NBCALipiodol $\circledast$ (Guerbet, France) mixture was determined after superselective angiography to assess the flow. Low concentration (about 20\%) was chosen for most cases but high concentrations (about 75\%) were chosen for high-flow fistulas. The microcatheters were flushed with a $25 \%$ dextrose solution and then the NBCA-Lipiodol mixture was infused under roadmap fluoroscopy. No reflux was permitted during NBCA injection. Rapid microcatheter withdrawal was done to prevent trapping of the microcatheter. All Patients were monitored in the intensive care unit after the procedure for 24 to 48 hours with maintaining mean arterial pressures between $65-$ and $75-\mathrm{mm} \mathrm{Hg}$ to prevent abrupt elevations in systolic blood pressure to reduce the risk of postembolization hemorrhage.

The number of veins, the embolic material used, and the percentage of nidal obliteration was registered as well as any complications related to the embolization procedure. Clinical and radiologic follow-up was done for all patients from 6 to 36 months.

\section{Statistical analysis of the data}

Data were fed to the computer and analyzed using IBM SPSS software package version 20.0. (Armonk, NY: IBM Corp). The Kolmogorov- Smirnov was used to verify the normality of distribution of variables, 
Comparisons between groups for categorical variables were assessed using Chi-square test (Fisher's Exact or Monte Carlo correction). Significance of the obtained results was judged at the $5 \%$ level

\section{Results}

This retrospective study included 140 patients diagnosed with brain AVMs since 2005 in our center. the whole patient cohort included 74 (53\%) females and 66 (47\%) males. Their age ranged from 7 to 43 years old with about one-third of patients less than 18 years. One hundred and eight patients (77\%) presented with hemorrhage. The AVM Spetzler-Martin grading showed grade II in $57(40.7 \%)$ patients and grade III in $56(39.3 \%)$ patients. Sixty-one (43.57\%) patients were treated by n-Butyl Cyanoacrylate and $71(50.71 \%)$ patients were treated with Onyx, and both materials were used together in 8 cases. The rate of complete occlusion in all patients was $61.43 \%$ (86 patients). There were three groups of patients, the first group had complete occlusion of the nidus at the time of embolization and included 68 (48.57\%) patients. The second group had partial embolization with partial occlusion of the nidus 54 (38.57\%). The 3rd group included 18 (12.85\%) patients with complete nidal occlusion on follow up after being partially embolized.

We compared the two groups of partially embolized cases as regards the angiographic observations that were associated with the progressive disappearance of the AVM nidus on follow up. These observations included the presentation with hemorrhage (15 patients 83.3\%, $\mathrm{p}<0.05$ ) (table 1 ), AVMs size less than 3 $\mathrm{cm}$ (16 patients $88.9 \%$ ), the presence of single draining vein (12 patients $66.7 \%$ ), superficial venous drainage (10 patients $55.6 \%$ ) and $1-3$ arterial feeders (15 patients $83.3 \%$ ). We observed that flow stasis and venous drainage delay to the late arterial phase or early venous phase was a significant predictor of late AVM obliteration. (Table 2), (figure 1,2, \&3).

The encountered complications related to the procedure were 7 cases of transient deficits, 6 cases of intraoperative rupture (4 cases of SAH and 2 cases of $\mathrm{ICH}$ required evacuation), 3 cases of catheter trapping, and 2 cases of permanent deficits. Also there was 7 cases of alopecia, and 5 cases of catheter entrapment. No procedure-related mortality occurred. The transient deficits included upper limb monoparesis in 3 cases improved in two weeks, transient hemiparesis in 2 cases due to intraoperative rupture, transient hemiparathesia in a thalamic AVM patient, and transient loss of consciousness in a thalamic AVM patient. The permanent deficit was hemiplegia in one patient due to intraoperative rupture. Another patient had pre-embolization weakness from intracerebral hematoma, the weakness increased after embolization and improved partially (grade 4 weakness) (Table 2).

\section{Discussion}

The most important presentation of brain AVMs is intracranial hemorrhage. AVM treatment aims to prevent future hemorrhage which may lead to mortality reaching about $41 \%$ in some series $[6,7,15,21,22,25]$. Most neurointerventionists aim to complete the eradication of the nidus during embolization. First, trans-arterial embolization was used followed nowadays with the transvenous route. The transarterial route may require multiple feeder navigation to reach the goal in one or more sessions. 
Multiple sessions were done to decrease complications associated with rapid hemodynamic changes after complete occlusion of the AVM. The transvenous route is now established with an effective role in the embolization of superficial AVMs $[6,8,13,14,18]$ Complications related to endovascular embolization of brain AVMs may occur secondary to the frequent arterial navigation using the microwire and microcatheter, also they may be related to the chemical properties of the embolizing agent or its excessive infusion $[6,8,13,17,18]$ The protective effect of embolization against hemorrhage was studied by Meisel et al [13]. Partial embolization can effectively obliterate weak points including aneurysms, venous ectasias, and high flow fistulas. Also, partial embolization was used before surgery to occlude deep feeders, high flow fistulas, and the weak points. This helped to decrease operative blood loss and shorten the procedure time. Also, partial embolization was used before radiosurgery to decrease the size, obliterate meningeal feeders, high flow fistulas, and the weak points[6,26]. Total nidal occlusion with angiographic disappearance of the feeders and veins during angiographic follow of 18 patients after partial embolization was observed in this study. During the embolization procedure, venous drainage delay and flow stasis after the arterial phase was observed and the infusion of the embolic agent was associated with more reflux. the procedure was stopped, and all patients were scheduled for follow-up. The eighteen patients had their AVM obliterated in follow up angiography after 6 to 36 months The radiological features that were shared in most of these cases that may explain this phenomenon included a presentation with hemorrhage, AVMs size less than $3 \mathrm{~cm}$, the presence of single draining or double draining veins, superficial venous drainage, and one or 2 arterial feeders. The stasis of flow and delay of venous drainage in our series is the best significant predictor that allows further thrombosis and closure of the nidus. Most of the venous drainage in spontaneously obliterated cases was a superficial one. Also, most lesions were small (about $89 \%$ were less than $3 \mathrm{~cm}$ ). also a low number of arterial feeders (one or two) was a significant predictor. NBCA is known to have a vascular inflammatory effect that may help thrombosis inside the AVM nidus[17]. several factors in the literature were discussed as the triggering mechanism for the AVM obliteration, these factors included the mass effect of parenchymal hemorrhage, vasospasm, and edema induced by $\mathrm{SAH}$, and atherosclerosis of the blood vessels of the nidus. Also, stasis and turbulence of the flow inside the nidus and draining vein may play a major role in thrombosis and obliteration. Limited number and stenosis of the draining veins also had an important effect in inducing thrombosis. Also, partial embolization may decrease the angiogenic factors affecting the endothelial cells followed by a reduction in size and obliteration[12,14,23,16,1-3,9,11,20,24,28]. Mangiafico et al[12]. reported one case with partial embolization progressed to angiographic obliteration and they observed reduction of the flow to the mid arterial phase. Cellerini et al[3]. reported 4 cases and they observed flow reduction after partial embolization. Ahmad et al[1]. Reported one case occluded after $70 \%$ occlusion of the nidus in 2 sessions. Kocur et al[9].and Torrico et al[24]. Each reported 2 cases after being embolized with onyx. Viñuela et al[28] reported 2 cases after use Isobutyl-2-Cyanoacrylate. Also, Nas et al[16] reported one case with partial embolization progressed to complete obliteration. Partial embolization may obliterate AVM through a hemodynamic change from certain angioarchitecture, the thrombogenic effect of the liquid embolic, and triggering of an inflammatory effect[17]. Miyachi et al [14] studied changes in drainage system after embolization and concluded that stasis in the venous outflow leads to progressive AVM thrombosis and obliteration. The achievement of complete nidal obliteration 
with embolization may require more microcatheter navigation or excessive infusion of the embolic agent which may be risky. Also, this may necessitate changing the decision by doing transvenous embolization or doing radiosurgery or microsurgery. So venous drainage delay may be an indication to stop the procedure especially with the reflux of the embolic material to a dangerous point. Follow-up angiography can be done later with the possibility of AVM cure. But long term follow-up is needed to ensure stable occlusion

\section{Conclusion}

spontaneous closure of intracranial arteriovenous malformations after partial embolization may be seen in cases of stasis of flow during embolization procedure with the delay of the venous drainage. A longterm follow-up of more cases over many years is required to confirm the stability of this conclusion.

\section{References}

1. Ahmad I, Tejada JG (2012) Progressive AVM Thrombosis after Onyx Embolization with Angiographic Cure. Neuroradiol J 20(6):750-754. doi:10.1177/197140091202500615. 25 ) .

2. Bendok BR, Getch CC, Ali MJ, Parish T, Batjer HH (2002) Spontaneous thrombosis of a residual arteriovenous malformation in eloquent cortex after surgery: case report. Neurosurgery 50(5):11421145. doi:10.1097/00006123-200205000-00038

3. Cellerini M, Mangiafico S, Villa G, Ammannati F, Giordano GP (2003) The disappearance of cerebral arteriovenous malformations after partial endovascular embolization: four cases with follow-up. Neuroradiology 45(12):916-920. DOI:10.1007/s00234-003-1104-z

4. Endo H, Osawa S, Matsumoto $\mathrm{Y}$ et al (2018) Embolization of ruptured arteriovenous malformations in the cerebellopontine angle cistern. Neurosurg Rev 41:173-182. https://doi.org/10.1007/s10143017-0832-1

5. Grüter BE, Sun W, Fierstra J et al (2021) Systematic review of brain arteriovenous malformation grading systems evaluating microsurgical treatment recommendation. Neurosurg Rev. https://doi.org/10.1007/s10143-020-01464-3

6. Hou K, Xu K, Chen X, Ji T, Guo Y, Yu J (2020) Targeted endovascular treatment for ruptured brain arteriovenous malformations. Neurosurg Rev 43(6):1509-1518. doi:10.1007/s10143-019-01205-1

7. Jiang X, Zhao Z, Zhang Y, Wang Y, Lai L (2021) Preradiosurgery embolization in reducing the postoperative hemorrhage rate for patients with cerebral arteriovenous malformations: a systematic review and meta-analysis. Neurosurg Rev. doi:10.1007/s10143-021-01530-4

8. Katsaridis V, Papagiannaki C, Aimar E (2008) Curative embolization of cerebral arteriovenous malformations (AVMs) with Onyx in 101 patients. Neuroradiology Jul 50(7):589-597. doi:10.1007/s00234-008-0382-x

9. Kocur D, Przybyłko N, Hofman M, Jamróz T, Doleżych H, Baron J, Kwiek S (2017) Progressive regression of intracranial arteriovenous malformations after Onyx embolization. Neurol Neurochir 
Pol May-Jun 51(3):270-275. doi:10.1016/j.pjnns.2017.03.005

10. Krings T, Hans FJ, Geibprasert S, Terbrugge K (2010) Partial "targeted" embolisation of brain arteriovenous malformations. Eur Radiol Nov;20(11):2723-2731. doi:10.1007/s00330-010-1834-3

11. Lim SL, Foo AS, Karlsson B, Yeo TT (2016) Spontaneous obliteration highlights the dynamic nature of cerebral arteriovenous malformations: A case report and review of the literature. Surg Neurol Int Apr 20:7:45. doi:10.4103/2152-7806.180766

12. Mangiafico S, Cellerini M, Villa G, Nistri M, Ammannati F, Giordano GP (2001) Disappearance of a cerebral arteriovenous malformation after partial endovascular embolisation. Interv Neuroradiol Mar 30(1):41-46. doi:10.1177/159101990100700106. 7 ).

13. Meisel HJ, Mansmann U, Alvarez H, Rodesch G, Brock M, Lasjaunias P (2002) Effect of partial targeted N-butyl-cyano-acrylate embolization in brain AVM. Acta Neurochir (Wien) Sep;144(9):879887. doi:10.1007/s00701-002-0978-6. discussion 888.

14. Miyachi S, Negoro M, Okamoto T, Otsuka G, Suzuki O, Sahara Y, Yoshida J (2001) Hemodynamic changes in drainage systems following treatment of cerebral arteriovenous malformations. Interv Neuroradiol. Dec 22;7(Suppl 1):89-98. doi: 10.1177/15910199010070S113

15. Mounayer C, Hammami N, Piotin M et al (2007) Nidal embolization of brain arteriovenous malformations using Onyx in 94 patients. AJNR Am J Neuroradiol 28:518-523

16. Nas OF, Ozturk K, Gokalp G, Hakyemez B (2017) Spontaneous occlusion of cerebral arteriovenous malformation following partial embolization with Onyx. Neuroradiol J Feb 30(1):96-98. doi:10.1177/1971400916678247

17. Natarajan SK, Born D, Ghodke B, Britz GW, Sekhar LN (2009) Histopathological changes in brain arteriovenous malformations after embolization using Onyx or N-butyl cyanoacrylate. Laboratory investigation. J Neurosurg Jul 111(1):105-113. doi:10.3171/2008.12.JNS08441

18. Ovalle F, Shay SD, Mericle RA (2012) Delayed intracerebral hemorrhage after uneventful embolization of brain arteriovenous malformations is related to volume of embolic agent administered: multivariate analysis of 13 predictive factors. Neurosurgery 70(2 Suppl Operative):313-320. doi:10.1227/NEU.0b013e3182357df3

19. Pierot $L$, van der Bom IM, Wakhloo AK (2012) Advances in stroke: advances in interventional neuroradiology. Stroke 43(2):310-313. doi:10.1161/STROKEAHA.111.642652

20. Pumar JM, Castiñeira JA, Vazquez F, Blanco M, Romero G, Baleato S, Ruibal C, Lazaro V (2007) Spontaneous regression of intracranial arteriovenous malformations. A report of two cases. Neuroradiol J 31(6):778-781. doi:10.1177/197140090601900614. 19 ) .

21. Saatci I, Geyik S, Yavuz K, Cekirge HS (2011 Jul) Endovascular treatment of brain arteriovenous malformations with prolonged intranidal Onyx injection technique: long-term results in 350 consecutive patients with completed endovascular treatment course. J Neurosurg 115(1):78-88. doi:10.3171/2011.2.JNS09830

22. Spetzler RF, Martin NA (1986) A proposed grading system for arteriovenous malformations. J Neurosurg 65(4):476-483. doi:10.3171/jns.1986.65.4.0476 
23. Sultan A, Hassan T, El-Saadany W et al (2014) Transarterial embolization of brain arteriovenous malformation; single-center experience. Neurosurg Q 24:27-36.

DOI:10.1097/WNQ.0b013e31828c70ad

24. Torrico TA, Tevah CJ (2006) Oclusión espontánea de malformación arteriovenosa cerebral parcialmente embolizada: reporte de dos casos [Spontaneous occlusion of previously cerebral embolized residual arteriovenous malformation: report of two cases]. Arq Neuropsiquiatr. 64(3A):681-5. Spanish. doi: 10.1590/s0004-282x2006000400032

25. Valavanis A, Pangalu A, Tanaka M (2005) Endovascular treatment of cerebral arteriovenous malformations with emphasis on the curative role of embolisation. Interv Neuroradiol. Oct 5;11(Suppl 1):37-43. doi: $10.1177 / 15910199050110 S 107$

26. van Beijnum J, van der Worp HB et al (2011) Treatment of brain arteriovenous malformations: a systematic review and meta-analysis. JAMA. Nov 9;306(18):2011-9. doi: 10.1001/jama.2011

27. Xu H, Wang L, Guan S, Li D, Quan T (2019) Embolization of brain arteriovenous malformations with the diluted Onyx technique: initial experience. Neuroradiology 61(4):471-478. doi:10.1007/s00234019-02176-2

28. Viñuela F, Fox AJ, Debrun G, Drake CG, Peerless SJ, Girvin JP (1983) Progressive thrombosis of brain arteriovenous malformations after embolization with isobutyl 2-cyanoacrylate. AJNR Am J Neuroradiol 4(6):1233-1238

\section{Tables}

Table (1): $\quad$ Comparison between the three studied groups according to demographic and clinical data: 


\begin{tabular}{|c|c|c|c|c|c|}
\hline & $\begin{array}{l}\text { Completely } \\
\text { obliterated } \\
(n=68)\end{array}$ & $\begin{array}{l}\text { Partially } \\
\text { obliterated } \\
(n=54)\end{array}$ & $\begin{array}{l}\text { Partially embolized with } \\
\text { complete obliteration } \\
(n=18)\end{array}$ & $\mathrm{P}_{1}$ & $\mathrm{p}_{2}$ \\
\hline \multicolumn{6}{|l|}{ Age (years) } \\
\hline $1-18$ & $13(19.1 \%)$ & $12(22.2 \%)$ & $4(22.2 \%)$ & \multirow[t]{2}{*}{0.902} & \multirow{2}{*}{$\begin{array}{l}\mathrm{FE}_{\mathrm{p}}= \\
1.000\end{array}$} \\
\hline$>18$ & 55 (80.9\%) & $42(77.8 \%)$ & $14(77.8 \%)$ & & \\
\hline \multicolumn{6}{|l|}{ Sex } \\
\hline Male & $33(48.5 \%)$ & $26(48.1 \%)$ & $7(38.9 \%)$ & \multirow[t]{2}{*}{0.753} & \multirow[t]{2}{*}{0.495} \\
\hline Female & 35 (51.5\%) & $28(51.9 \%)$ & $11(61.1 \%)$ & & \\
\hline \multicolumn{6}{|l|}{ Presentations } \\
\hline Hemorrhage & 59 (86.8\%) & 34 (63\%) & 15 (83.3\%) & \multirow{3}{*}{$\begin{array}{l}{ }^{M C} p= \\
0.022^{*}\end{array}$} & \multirow{3}{*}{$\begin{array}{l}{ }^{M C} C_{p}= \\
0.251\end{array}$} \\
\hline Fits & $6(8.8 \%)$ & $16(29.6 \%)$ & $2(11.1 \%)$ & & \\
\hline $\begin{array}{l}\text { Headache\& } \\
\text { others }\end{array}$ & $3(4.4 \%)$ & $4(7.4 \%)$ & $1(5.6 \%)$ & & \\
\hline \multicolumn{6}{|l|}{ Location } \\
\hline Frontal & $9(13.2 \%)$ & $12(22.2 \%)$ & $3(13.7 \%)$ & \multirow{10}{*}{$\begin{array}{l}\mathrm{MC}_{\mathrm{p}}= \\
0.285\end{array}$} & \multirow{10}{*}{$\begin{array}{c}\mathrm{MC}_{\mathrm{p}}= \\
0.800\end{array}$} \\
\hline Parietal & $18(26.6 \%)$ & $14(25.9 \%)$ & $7(38.9 \%)$ & & \\
\hline Temporal & $6(8.8 \%)$ & $8(14.8 \%)$ & $4(22.2 \%)$ & & \\
\hline Occipital & $21(30.9 \%)$ & $7(13 \%)$ & $3(16.7 \%)$ & & \\
\hline IV & $4(5.9 \%)$ & $2(3.7 \%)$ & $0(0 \%)$ & & \\
\hline BG & $1(1.5 \%)$ & $0(0 \%)$ & $0(0 \%)$ & & \\
\hline Callosal & $3(4.4 \%)$ & $1(1.9 \%)$ & $0(0 \%)$ & & \\
\hline TH & $1(1.5 \%)$ & $4(7.4 \%)$ & $1(5.6 \%)$ & & \\
\hline BS & $2(2.9 \%)$ & $0(0 \%)$ & $0(0 \%)$ & & \\
\hline CBLR & $3(4.4 \%)$ & $6(11.1 \%)$ & $0(0 \%)$ & & \\
\hline
\end{tabular}

\section{FE: Fisher Exact MC: Monte Carlo}

$p_{1}: p$ value for comparing between the three studied groups

$\mathrm{p}_{2}: \mathrm{p}$ value for comparing between Incomplete and Partial complete

*: Statistically significant at $p \leq 0.05$ 
Table (2): Comparison between the groups according to imaging criteria 


\begin{tabular}{|c|c|c|c|c|c|}
\hline & $\begin{array}{l}\text { Completely } \\
\text { obliterated } \\
(n=68)\end{array}$ & $\begin{array}{l}\text { Partially } \\
\text { obliterated } \\
\quad(n=54)\end{array}$ & $\begin{array}{l}\text { Partially embolized } \\
\text { complete obliteratic } \\
(n=18)\end{array}$ & $\begin{array}{l}\text { with } \\
\text { n }\end{array}$ & $\mathrm{P}_{2}$ \\
\hline $\begin{array}{l}\text { Spetzler martin } \\
\text { grade }\end{array}$ & & & & & \\
\hline I & $5(7.4 \%)$ & $1(1.9 \%)$ & $3(16.7 \%)$ & \multirow{5}{*}{$\begin{array}{l}{ }^{M C} C_{p}= \\
0.021^{*}\end{array}$} & \multirow{5}{*}{$\begin{array}{l}M C_{p}= \\
0.208\end{array}$} \\
\hline II & $36(52.9 \%)$ & $15(27.8 \%)$ & $6(33.3 \%)$ & & \\
\hline III & $22(32.4 \%)$ & $26(48.1 \%)$ & $7(38.9 \%)$ & & \\
\hline IV & $4(5.9 \%)$ & $10(18.5 \%)$ & $2(11.1 \%)$ & & \\
\hline V & $1(1.5 \%)$ & $2(3.7 \%)$ & $0(0 \%)$ & & \\
\hline \multicolumn{6}{|l|}{ Number of feeders } \\
\hline 1 feeder & $21(30.9 \%)$ & $0(0 \%)$ & $2(11.1 \%)$ & \multirow{5}{*}{$\begin{array}{l}{ }^{M C} p \\
<0.001^{*}\end{array}$} & \multirow{5}{*}{$\begin{array}{l}{ }^{M C} c_{p} \\
<0.001^{*}\end{array}$} \\
\hline 2 feeders & $18(26.5 \%)$ & $6(11.1 \%)$ & $6(33.3 \%)$ & & \\
\hline 3 feeders & $12(17.6 \%)$ & $10(18.5 \%)$ & $7(38.9 \%)$ & & \\
\hline 4 feeders & $5(7.4 \%)$ & $8(14.8 \%)$ & $1(5.6 \%)$ & & \\
\hline 5 or more feeders & $12(17.6 \%)$ & $30(55.6 \%)$ & $2(11.1 \%)$ & & \\
\hline \multicolumn{6}{|l|}{$\begin{array}{l}\text { Type of venous } \\
\text { drainage }\end{array}$} \\
\hline Deep (D) & $13(19.1 \%)$ & $11(20.4 \%)$ & $4(22.2 \%)$ & \multirow{3}{*}{$\begin{array}{l}M C_{p}= \\
0.474\end{array}$} & \multirow{3}{*}{$\begin{array}{c}M C_{p}= \\
0.209\end{array}$} \\
\hline Superficial (S) & $31(45.6 \%)$ & $19(35.2 \%)$ & $10(55.6 \%)$ & & \\
\hline Both (SD) & $24(35.3 \%)$ & $24(44.4 \%)$ & $4(22.2 \%)$ & & \\
\hline \multicolumn{6}{|l|}{ Number of veins } \\
\hline One vein & $34(50 \%)$ & $15(27.8 \%)$ & $12(66.7 \%)$ & \multirow[t]{3}{*}{$<0.001^{*}$} & \multirow[t]{3}{*}{$0.006^{*}$} \\
\hline 2 veins & $25(36.8 \%)$ & $13(24.1 \%)$ & $4(22.2 \%)$ & & \\
\hline 3 or more veins & $9(13.2 \%)$ & $26(48.1 \%)$ & $2(11.1 \%)$ & & \\
\hline \multicolumn{6}{|l|}{ AVM size $(\mathrm{cm})$} \\
\hline$<3$ & $50(73.5 \%)$ & $21(38.9 \%)$ & $16(88.9 \%)$ & \multirow{3}{*}{$\begin{array}{l}{ }^{M C} \mathrm{p}_{\mathrm{p}} \\
<0.001^{*}\end{array}$} & \multirow{3}{*}{$\begin{array}{l}{ }^{M C} p= \\
0.001^{*}\end{array}$} \\
\hline $3-6$ & $18(26.5 \%)$ & $29(53.7 \%)$ & $2(11.1 \%)$ & & \\
\hline$>6$ & $0(0 \%)$ & $4(7.4 \%)$ & $0(0 \%)$ & & \\
\hline \multicolumn{6}{|l|}{ Material used } \\
\hline NBCA & $32(47.1 \%)$ & $20(37 \%)$ & $9(50 \%)$ & $\begin{array}{l}M C_{p}= \\
0.574\end{array}$ & $\begin{array}{c}M C_{p}= \\
0.444\end{array}$ \\
\hline
\end{tabular}




\begin{tabular}{|c|c|c|c|c|c|}
\hline Onyx & $33(48.5 \%)$ & $29(53.7 \%)$ & $9(50 \%)$ & & \\
\hline Both & $3(4.4 \%)$ & $5(9.3 \%)$ & $0(0 \%)$ & & \\
\hline \multicolumn{6}{|l|}{ No of sessions } \\
\hline 1 & $62(91.2 \%)$ & 32 (59.3\%) & 16 (88.9\%) & \multirow{3}{*}{$\begin{array}{l}\mathrm{MC}_{\mathrm{p}}= \\
0.001^{*}\end{array}$} & \multirow{3}{*}{$\begin{array}{l}\mathrm{MC}_{\mathrm{p}}= \\
0.094\end{array}$} \\
\hline 2 & $4(5.9 \%)$ & $11(20.4 \%)$ & $1(5.6 \%)$ & & \\
\hline$\geq 3$ & $2(2.9 \%)$ & $11(20.4 \%)$ & $1(5.6 \%)$ & & \\
\hline \multicolumn{6}{|l|}{ Complications } \\
\hline Transient deficit & $3(4.4 \%)$ & $3(5.6 \%)$ & $1(5.6 \%)$ & ${ }^{M C} p=1.000$ & $\mathrm{FE}_{p}=1.000$ \\
\hline Permanent & $2(2.9 \%)$ & $0(0 \%)$ & $0(0 \%)$ & ${ }^{M C} c_{p}=0.629$ & - \\
\hline intraoperative & $5(7.4 \%)$ & $1(1.9 \%)$ & $0(0 \%)$ & \multirow[t]{3}{*}{${ }^{M C} C_{p}=0.337$} & \multirow[t]{3}{*}{$\mathrm{FE}_{\mathrm{p}}=1.000$} \\
\hline & 4 (5.89\%) & $2(3.7 \%)$ & $1(5.6 \%)$ & & \\
\hline $\begin{array}{l}\text { Alopecia } \\
\text { Catheter } \\
\text { entrapment }\end{array}$ & $3(4.4 \%)$ & $2(3.7 \%)$ & $0(0 \%)$ & & \\
\hline \multicolumn{6}{|c|}{$\begin{array}{l}\text { Status of venous } \\
\text { drainage after EVE }\end{array}$} \\
\hline $\begin{array}{l}\text { Early arterial } \\
\text { drainage }\end{array}$ & - & 29 (53.7\%) & $0(0 \%)$ & - & \multirow{4}{*}{$\begin{array}{l}{ }^{M C}{ }_{p} \\
<0.001^{*}\end{array}$} \\
\hline $\begin{array}{l}\text { Late arterial } \\
\text { drainage }\end{array}$ & - & $20(37 \%)$ & $16(88.9 \%)$ & & \\
\hline $\begin{array}{l}\text { Mid arterial } \\
\text { drainage }\end{array}$ & - & $5(9.3 \%)$ & $0(0 \%)$ & & \\
\hline $\begin{array}{l}\text { Venous phase } \\
\text { drainage }\end{array}$ & - & $0(0 \%)$ & $2(11.1 \%)$ & & \\
\hline
\end{tabular}

FE: Fisher Exact. MC: Monte Carlo $p_{1}: p$ value for comparing between the three studied groups.

$\mathrm{p}_{2}: \mathrm{p}$ value for comparing between Partially obliterated and Partially embolized with complete obliteration *: Statistically significant at $p \leq 0.05$

\section{Figures}



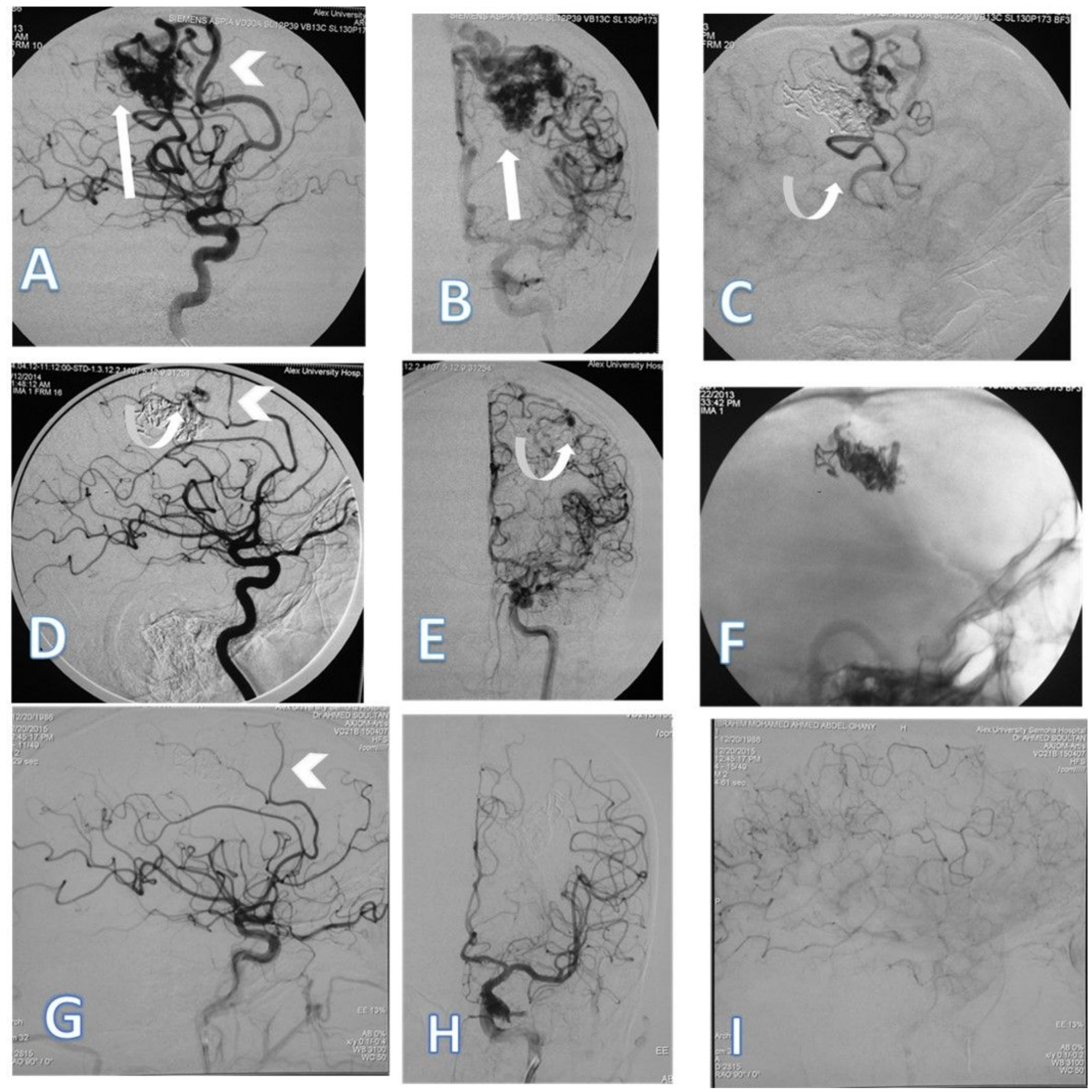

\section{Figure 1}

A 33 years patient presented with IVH and hydrocephalus A: Plain CT scan axial showing IVH, B: LT vertebral artery (VA) angiography showing Rt the AVM supplied by RT PCA branches(straight arrow), C: LT ICA angiography showing the AVM supplied by anterior choroidal branches(straight arrow) D:

superselective angiography for the second NBCA injection(straight arrow), E: Lt VA angiography showing nidus remnant (curved arrow), F: axial T2 MRI follow showing nidus disappeared and normal ventricular 
size G\&H: late RT VA angiography showing nidus disappeared I: late RT ICA angiography showing nidus disappeared
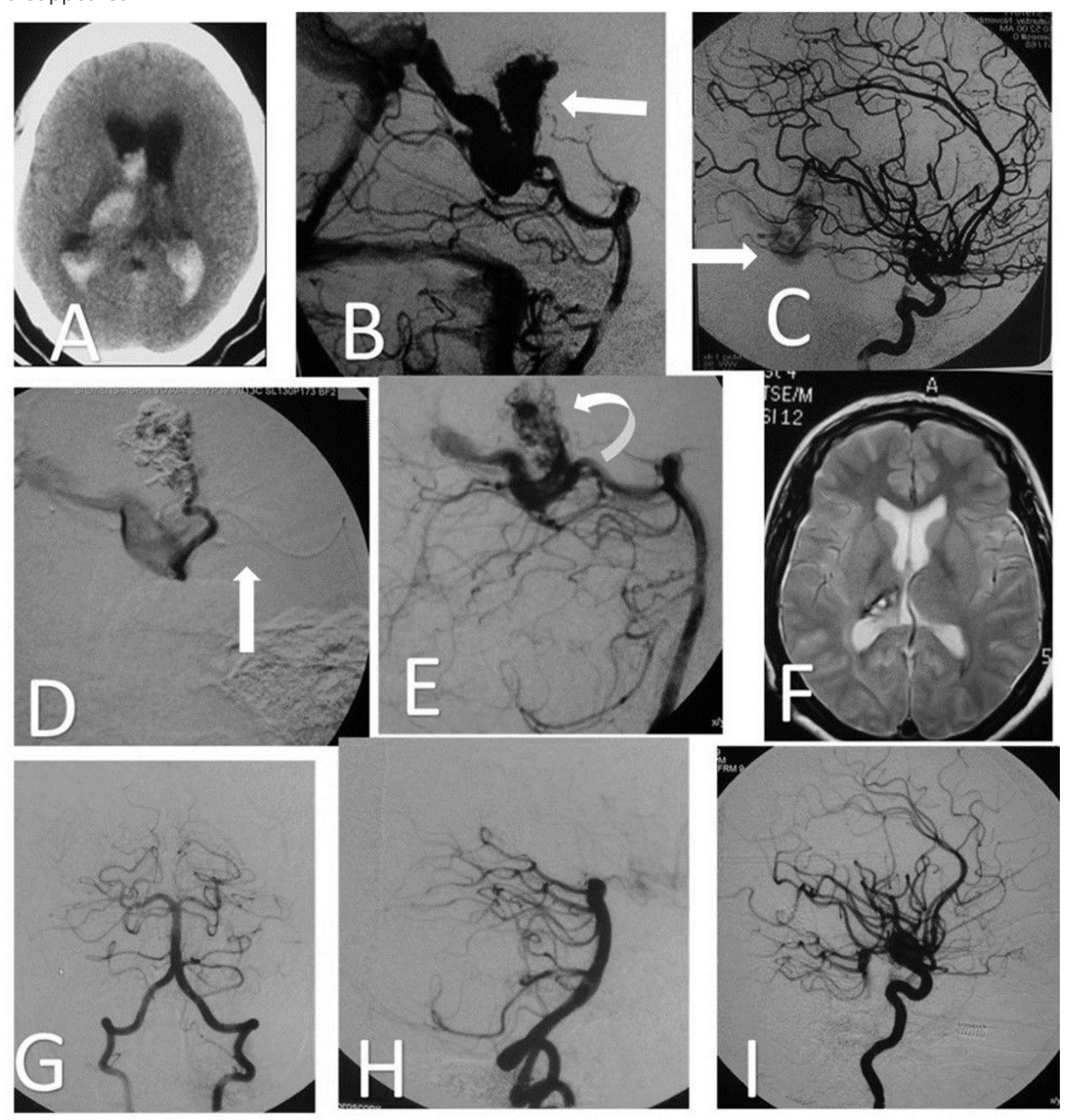

\section{Figure 2}

A twenty-seven years old patient presented with ICH A\&B: LT ICA angiography showing Lt frontal AVM supplied by ACA \&MCA branches (straight arrow), D\&E: left ICA angiography (lateral and anteroposterior views) showing nidus remnant (curved arrow) C: left ICA angiography (lateral view) showing nidus 
remnant (curved arrow) in late arterial phase, $F$ : plain radiograph showing the onyx cast in lateral view G, $\mathrm{H}$, l: late LT ICA angiography after one year showing nidus disappeared (feeders are regressed in size the arrowheads point to the feeders in $A, D, \& G$ ).
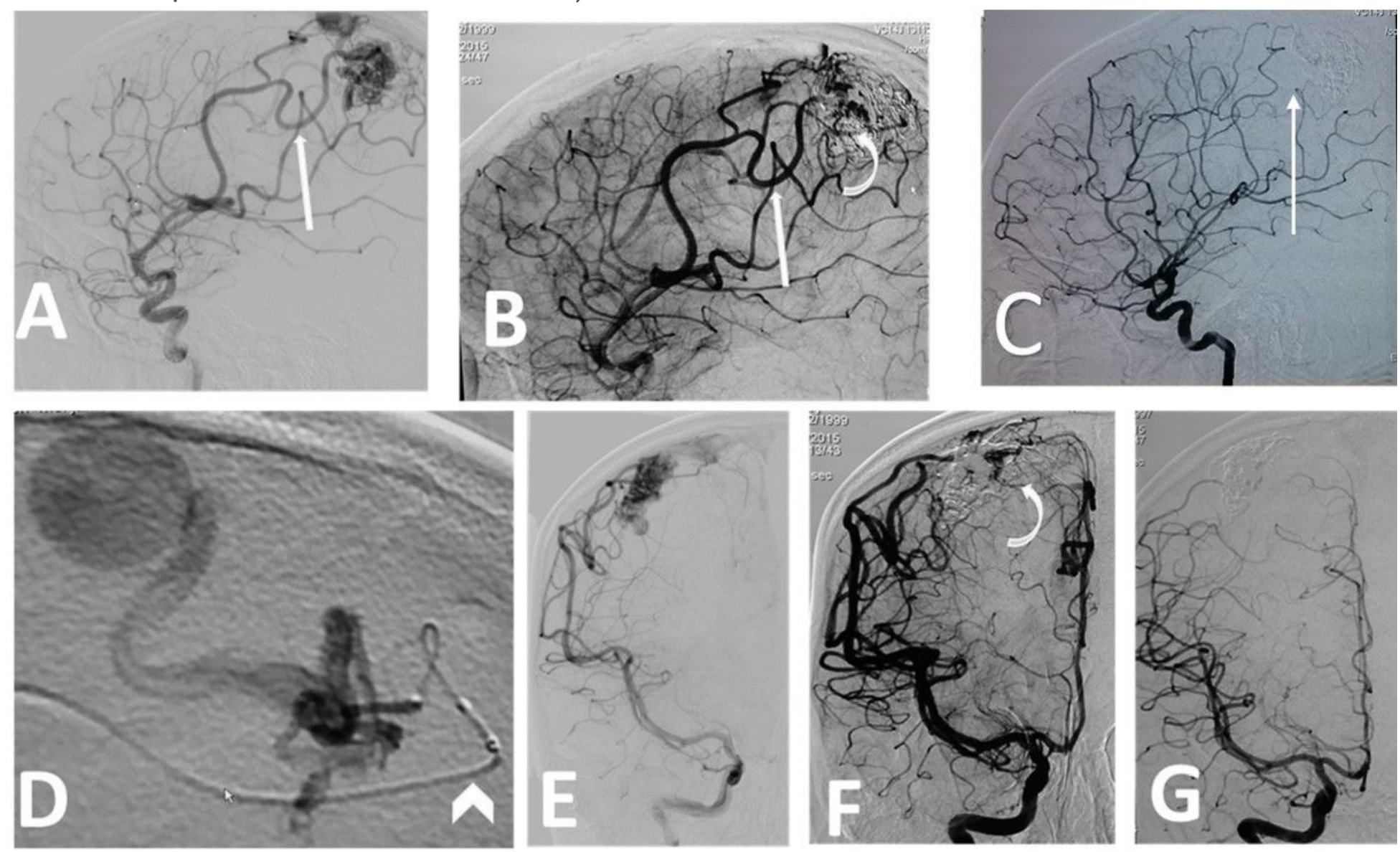

\section{Figure 3}

A fifteen years old patient presented with ICH A\&E: Right ICA angiography (lateral \&anteroposterior views) showing Rt parietal AVM supplied by MCA branches (a straight arrow pointing to the main feeder ), B\&F: Rt ICA angiography (lateral and anteroposterior views) showing nidus remnant (curved arrow) after embolization with, D: superselective angiography (arrowhead pointing to the microcatheter) showing venous aneurysm. C\&G: Follow up RT ICA angiography after 4 months showing nidus disappeared and the main feeder also obliterated and disappeared (straight arrow). 